\section{LIBRI}

www.libridergi.org

Kitap Tanıtımı, Eleştiri ve Çeviri Dergisi

Journal of Book Notices, Reviews and Translations

Volume II (2016)

F. PIRSON \& A. SCHOLL (Eds.), Anadolu'da Hellenistik Bir Başkent Pergamon. İstanbul 2014. Yapı Kredi Yayınları, 552 sayfa (163 resim, 89 çizim ve 5 harita ile birlikte). ISBN: 9789750831003

\section{Mehmet KÜRKÇÜ}

Libri: Kitap Tanıımı, Eleştiri ve Çeviri Dergisi'nde bulunan içeriklerin tümü kullanıcılara açık, serbestçe/ücretsiz 'açık erişimli' bir dergidir. Kullanıılar, yayıncıdan ve yazar(lar)dan izin almaksızın, dergideki kitap tanıtımı, eleştiri ve çevirileri tam metin olarak okuyabilir, indirebilir, dağıtabilir, çıktııını alabilir ve kaynak göstererek bağlantı verebilir.

Libri, uluslararası hakemli elektronik (online) bir dergi olup değerlendirme süreci biten kitap tanıtımı, eleştiri ve çeviriler derginin web sitesinde (www.libridergi.org) yıl boyunca ilgili sayının içinde (Volume II: Ocak-Aralık 2016) yayımlanır. Aralık ayı sonunda ilgili yıla ait sayı tamamlanır.

Dergide yayımlanan eserlerin sorumluluğu yazarlarına aittir.

Atıf Düzeni M. Kürkçü, Anadolu'da Hellenistik Bir Başkent Pergamon. Eds. F. Pirson - A. Scholl. Libri II (2016) 81-88. DOI: 10.20480/lbr.2016005

Geliş Tarihi: 25.01.2016 | Kabul Tarihi: 12.03.2016 | Online Yayın Tarihi: 14.03.2016

URL: http://dx.doi.org/10.20480/lbr.2016005

Editörya Phaselis Project

www.phaselis.org 


\title{
F. PIRSON \& A. SCHOLL (Eds.), Anadolu'da Hellenistik Bir Başkent Pergamon. İstanbul 2014. Yapı Kredi Yayınları, 552 sayfa \\ (163 resim, 89 çizim ve 5 harita ile birlikte). ISBN: 9789750831003
}

\begin{abstract}
Mehmet KÜRKÇÜ*
Editörlüğü Felix Pirson ve Andreas Scholl tarafından üstlenilen, ayrıca Giriş (12-15) bölümü de yine editörlerince kaleme alınan bu eser W. Radt'ın 2002 yılında Türkçe yayınlanan Pergamon adlı kitabının devamı niteliğini taşımaktadır. 2011/12 yıllarında Berlin'de düzenlenen "Pergamon: Bir Antik Dönem Metropolünün Panoraması" isimli serginin kataloğunda kentle ilgili son dönem çalışmalara yer verilmiştir. Akabinde, krallık başkenti olan Pergamon'un, halkı ve tanrılarıyla birlikte bir yaşam alanı şeklinde sunulması istemiyle yeni makaleler kaleme alınarak çalışma zenginleştirilmiş ve uluslararası okuyucu kitlesine ulaşacak şekilde Türkçe ve İngilizce olarak iki dilde hazırlanmıştır. Ayrıca eserin başında Pergamon - Antik Metropolis Panoraması isimli dört sayfalık bir rekonstrüksiyon çalışması da yer almaktadır.
\end{abstract}

26 yazarın katkıda bulunduğu toplam 30 adet bildiri, Araştırma ve Koruma (19-105), Tarih ve Çevre (106-187), Kent Gelişimi, Şehircilik ve Mimari (188-261), insanların Yaşam Alanları (262379) ve son olarak da Tanrıların Mekânları (380-551) başlıklı 5 ana bölümde okuyucuya sunulmaktadır.

Araştırma ve Koruma isimli birinci bölümde beş adet bildiri yer almaktadır: Ilk bildiri U. Kästner'in "O kadar yüce ve muhteşem bir eser ki... Dünyaya bir kez daha bahşedilmiş gibi" (C. Humann 1880) - 1900 Yılına Kadar Pergamon Kazılarının Tarihçesi (20-35) başlığını taşımaktadır. Bildiride kazıların başlangıç dönemi öncesinde bölgeye gelenler ve Carl Humann'ın izlenimlerine yer verilmektedir. Bu kapsamda, 1878 yılı Ağustos ayında Osmanlı Devleti Maarif Nazırı Mehmet Tahir Münif Paşa'nın Alman Konsolosu F. A. Tettenborn'a verdiği kazı izniyle başlayan C. Humann'ın çalışmalarına ve de 1884 yılından itibaren araştırmaların disiplinlerarası bir projeye dönüşmesine değinilmektedir. İki yıl sonra su sistemlerinin incelenmeye başlanmasıyla çevrenin etüt edilmesi günümüzde gerçekleştirilen kent çevrelerinin araştırılmasına öncülük ettiği anlatılmaktadır. Bildirinin son bölümü ise eserlerin paylaşımı ve Berlin'e taşınmasına ayrılıştır.

Wolfgang Radt'ın kaleminden çıkan "Artık eğlence ve oyun bitti!" (A. Conze 1904) - 20. Yüzyıldaki Pergamon Kazıları (38-47) isimli diğer bildirinin giriş bölümünde, Pergamon kazılarının başlangıcından itibaren kazı ekibine bilimsel danışmanlık yapan, aynı zamanda Alman Arkeoloji Enstitüsü Berlin Şubesi'nin başına getirilen ve de "Pro Pergamo" sloganını ilk kez kullanan A. Conze'nin uğraşları sonucu Alman Arkeoloji Enstitüsü Atina Şubesi Müdürü Wilhelm Dörpfeld'in 1900 yılında Pergamon kazı başkanlığını üstlenmesine değinilir. Devamında bu tarihte "Müze

\footnotetext{
* Dr., Université de Sorbonne, Paris. mhmtkurkcu@gmail.com
} 
Kazıları" olmaktan çıkıp bilimsel araştırmalara dönüşen çalışmaların tarihçesine yer verilmekte ve 2005 yılından bu yana kazıları sürdüren Felix Pirson'un programının amacına değinilmektedir.

Kazı başkanı Felix Pirson tarafından Kent ve Çevresi: Gelenek ve Yenilik Arasında Pergamon Araştırmaları (50-63) adıyla sunulan bildiride kültür tarihi tartışmalarının temel dayanaklarını oluşturan kentsel sistemin işleyişi, kenti çevreleyen mahalleler, yakın çevre ve bunlarla ilgili mekânlara ait verilerin birbirleriyle bağlantıları ve Pergamon kazılarında geliştirilen modüler belgeleme sistemi iDAlfield ele alınmaktadır. Teknolojik gelişmelerden yararlanarak birbirinden bağımsız, farklı bölgelerden elde edilen verilerin birleştirilerek değerlendirilmesi sonucunda kentin sosyal, ekonomik ve politik yapısını yansıtan kentsel yaşam alanları ve maddi kültür kalıntıları irdelenmektedir. Üstlendikleri Pergamon misyonunun bilincinde olarak yeni kazı- araştırma teknikleri uygulanarak geleceğe yönelik perspektifler sunulmaktadır.

Andreas Scholl, Pergamon, Bir Antik Dönem Metropolünün Panoraması Berlin'deki Pergamon Araştırmalarının Kaynaştırıcı Etkeni ve Vitrini Olarak Pergamon Sergisi (66-77) isimli bildirisinde serginin hazırlanması sürecinde izlenen yol, sergi konsepti, salonun hazırlanması gibi konuların yanında bu süreç içerisinde düzenlenen ve en önemli bilimsel aktivite olarak değerlendirdiği "Hellenistik sanatın merkezi olarak Pergamon - önemi, kendine özgü yanları ve etkileri" adlı sempozyum ve serginin uluslararası medyada gördüğü ilgiden bahsetmektedir. Yine 2016 yllında New York Metropolitan Museum of Art'ta, içerisinde Berlin'deki Antik Eserler Kolleksiyonu'nun da yer alacağı "Pergamon and the Hellenistic Kingdom" adıyla bir sergi açılması planlandığı bildiride belirtilmektedir.

Martin Bachmann'ın sunduğu Ortaya Çıkarmak ve Korumak: Pergamon'da 130 Yıllık Restorasyon Tarihçesi (80-101) isimli bildiride 19. yüzyıl sonlarında Almanya'daki anıt koruma teorilerinin hayata geçirilerek zaman içerisinde geliştirilip zenginleştirilmesi ve bunun sonucunda da Pergamon'a özgü bir restorasyon geleneğinin oluşturulması ele alınmaktadır. Bu bağlamda kentte kazıların başlangıından serginin yapıldığı 2012 yılına kadarki restorasyon çalışmaları, İlk Restorasyonlar, Traianeum'daki Kısmi Anastilosis Çalışmaları, Z Binası'ndaki Mozaikleri Koruma Çatısı, Kızı Avlu'daki Restorasyon Çalışmaları ve de Gymnasionun Konservasyonu başıkları altında okuyucunun bilgisine sunulmaktadır.

Tarih ve Çevre isimli bölümde dört adet bildiri yer almaktadır: Tarih Öncesi Dönemde Pergamon ve Bakırçay (Kaikos) Ovası (106-119) isimli bildirinin giriş bölümünde Barbara Horejs çalışılan alanın sınırlarını verdikten sonra bu alanda gerçekleştirilen araştırmalarda bölgenin tarih öncesi dönemlerdeki önemi ve gelişimine ayrılan çalışmaların azlığına değinerek çalışmalarını bu şekilde yönlendirdiklerinden bahsetmiştir. İzleyen bölümde öncüllerinin yürüttüğg̈ eski araştırmalar ve bulgulardan bahseden Horejs ardından Pergamon'un yakın çevresinin Prehistoryasına dair güncel araştırmaları ve sonuçları, Tarih Öncesi Yerleşimlerin Konumu ve Genişlemesi, Hammade Kaynakları ve Bağlantı Noktaları, Bakırçay Ovası'ndaki En Eski İzler, Geç Kalkolitik ve Erken Tunç Çağı (MÖ IV-III. binyıllar) ve son olarak da Orta ve Geç Tunç Çağı (II. binyıl) başıkları altında okuyucuya sunmaktadır.

Hans-Joachim Gehrke Bir Antik Dönem Metropolünün Tarihçesi (122-141) isimli bildirisinin giriş bölümünde, iskânın Arkaik Dönem'de başladığı ve MÖ VI. yüzyılda etrafı surla çevrilerek kale yerleşmesine dönüştüğü "Pergamon Tepesi" ile çevresini ve bu bölgedeki etnik grupları tanımlamakta, Hellenlerle yaşanan kültürel yakınlaşma ve sonuçlarını irdelemektedir. Küçük Kale yerleşiminin antik dönemin en önemli merkezlerinden biri oluş sürecinde Philetairos'un en 
önemli role sahip olmasını sebepleriyle açıkladıktan sonra ardıllarının uyum ve becerilerini sıralamakta, krallığın çok uzun ömürlü olmasının sebebi olarak da Attalos Hanedanı'nın gösterdiği dayanışmaya vurgu yapmaktadır. Bildiride kentin tarihçesi, politik tutumu, savaşlar, Roma ile ilişkiler ve bayındırlık çalışmalarının yanı sıra Doğu Roma Dönemi'nde Arapların istilalarıyla yerleşimin küçülmeye başlaması ve Osmanlı egemenliğine geçişine yer verilmiştir.

F. Pirson ve M. Zimmermann'ın ortak kaleme aldıkları Pergamon ve Çevresi: Ekonomik Kaynaklar, Taşra Yerleşmeleri ve Siyasi Gücün Temsili (144-161) başlıklı bildiride kentin çevresinde yapılan çalışmaların önemine vurgu yapılmakta, elde edilen verilerin sosyo-ekonomi, tarih ve demografi araştırmalarına sağladığı devrimsel katkılar belirtilmektedir. Ayrıca yaklaşık yüz yıllık bir aradan sonra 2006 yılında yeniden başlanan sistemli yakın çevre araştırmalarının sonuçları paylaşılmaktadır. Araştırmacılar bu çalışmaların temel hedeflerinin Pergamon'un Prehistorik çağlardan Doğu Roma Dönemi'ne kadar olan evrelerinin rekonstrüksiyonunu yapmak olduğunu ifade etmektedirler. Bakırçay Ovası, Kent ve Çevresi ve son olarak da Pergamon ve Komşu Kentler: Elaia ve Atarneus başlıklı bölümlerdeyse, yapılan çalışmalar sonucunda elde ettikleri gözlemleri okuyucuyla paylaşmaktadırlar.

Bizans Dönemi'nde Pergamon (164-183) başlığında Thomas Otten, ilgili dönemde kent hakkındaki bilgilerin kısıtlı olduğu ve Doğu Roma yerleşkesine dönüşme sürecinde yaşanan Karanlık Çağ'ın hemen öncesindeki evreleri (MS III-IV. yüzyıllar), 1970'lerde başlayıp 1990'lara değin devam eden süreç içerisindeki kazılarda bulunan resmi ve diğer önemli yapıların analizlerini yaparak değerlendirmektedir. Elde edilen veriler; Geç Antik ve Erken Bizans Dönemleri, Geç Roma İmparatorluk Dönemi Kalesi, Erken Bizans Dönemi Kiliseleri, Erken Bizans Kalesi, Erken Bizans Dönemi Yerleşmesi, Erken Bizans Döneminde Asklepieion, Erken Bizans Dönemi Mezarları, Orta Bizans Dönemi (IX. yüzyıl sonu ile XI. yüzyıl sonu arası), Traianeum'daki Mezarlar, Geç Bizans Dönemi (XII. yüzyıl-XIII. yüzyılın sonu), Geç Bizans Surları, Geç Bizans Dönemi Yerleşmesi, Geç Bizans Dönemi Kiliseleri ve Mezarlıkları ile son olarak Kalenin Türkler Tarafından Ele Geçirilmesi başlıkları altında sunulmaktadır.

Kent Gelişimi, Şehircilik ve Mimari isimli bölümde beş adet bildiri yer almaktadır: Antik Pergamon Kentinin Konumu ve Gelişimi (188-205) isimli bildiride kentin farklı evreleri ve geçirdiği değişimler Wolfgang Radt tarafından Antik Pergamon Kentinin Sur Duvarları, Pergamon'un Erken Dönemleri (yaklaşık MÖ 200 ile MÖ 300 arası), Philetairos Dönemi (MÖ III. yüzyılın birinci yarısı), I. Attalos Dönemi (MÖ III. yüzyılın ikinci yarısı), II. Eumenes ve II. Attalos Dönemleri (MÖ II. yüzyılın ilk yarısı), Pergamon'da Roma Imparatorluk Dönemi (MÖ 133 - MS III. yüzyıl) ve Geç Roma ve Erken Bizans Dönemi (MS III. yüzyıl sonu - VII. yüzyıl) başlıkları altında değerlendirilmektedir.

F. Pirson'un Hellenistik Dönem Pergamonu'nda Kentsel Alan ve Şehircilik (208-225) isimli bildirisinde MÖ II. yüzyılda kent mimarisinin topografya ile tamamlanan uyum süreci ve Pergamon şehirciliği sırasıyla Kentsel Alandaki Hiyerarşi, Kentsel Alanda İşlevsel ve Sosyal Ayrım, Kent Alanının Bölümlere Ayrıması ve Hellenistik Dönem'deki Geniş Kapsamlı Kentsel Dönüşüm ve Genişleme başlıkları altında ele alınmaktadır.

M. Bachmann'ın Pergamon Mimarisi ve Yapı Teknikleri (228-243) başlığının ilk bölümünde Pergamon Tepesi'ndeki mevcut doğal alanın niteliklerine odaklanılmaktadır. Diğer yandan, kentin çarpıcı ve çetin topografyasıyla nasıl başa çıkıldığı üzerinde de durulmakta ve geliştirilen teknik buluş ve çözümlerin Pergamon'a özgü bir yapı sanatının oluşturulmasındaki etkileri vurgu- 
lanmaktadır. Söz konusu yapı sanatının özgün teknik özellikleri ise ikinci bölümün konusunu oluşturmaktadır. Yazar bildirisini Mimarinin Üstesinden Gelmek Zorunda Kaldığı Doğal Arazi Yapısı, Pergamon Yapı Teknikleri ve Organizasyonu, Kentin Yapılarındaki Pergamon'a Özgü Yanlar ve Pergamon Mimarisinin Siyasi Mesajı başlıkları altında okuyucuya sunmaktadır.

Henning Fahlbusch'un kaleme aldığı Antik Pergamon'da Su Temini (246-257) bildirisinin konusunu Pergamon Kenti'nin su sistemlerinin gelişimi ve genel özellikleri oluşturmaktadır. Fahlbusch konuyu Su Kaynakları ve Sarnıçlar, Hellenistik Dönem Su Yolları ve Roma İmparatorluk Dönemi Su Kanalları adlı başıklar altında incelemekte ve küçük bir kale yerleşiminden önemli bir krallığa başkentlik yapacak kadar büyük bir kente dönüşen Pergamon'da kent sakinlerine suyun sağlanma yöntemlerini ortaya koymaktadır. Bildirinin 255. sayfasında yer alan bölümünde önemli bir çeviri hatası bulunmaktadır. İngilizce metinde yer alan "precious lead" deyimi Türkçe metinde "değerli bakırlar" olarak geçmektedir. Söz konusu döneme ait suyollarında bakır kullanılmadığı bilindiğinden ileride olması muhtemel yanlış kullanım ve anlamaların önüne geçmek için gelecek baskılarda bu çevirinin doğru olan "değerli kurşun" şeklinde düzeltilmesi uygun olacaktır.

Insanların Yaşam Alanları isimli bölümde yedi adet bildiri yer almaktadır: Helmut Müller'in Bir Kent Olarak Pergamon: Kurumlar, Görevliler ve Halk (262-273) bildirisinin giriş bölümünde "Pergamon Kronikleri" olarak tanınan ve kent tarihçesini içeren bir metin esas alınarak Pergamon'un Pers Hükümdarlığı altında olmasına rağmen, bir polis olarak MÖ IV. yüzyılın ilk yarısında karşımıza çıktığını belirtmektedir. Devamında aynı metinde Arkhias isimli bir kişinin prytanis olarak görev yaptığını ve bu memuriyetteki ilk kişi olduğunu, söz konusu memuriyetteki şahısların yazılı kaynakların artık bir bilgi vermediği Geç Roma İmparatorluk Dönemi'ne kadar görevli oldukları yılları kendi adlarıyla kaydettiklerini de ilave eder. Bildiride kentteki kurumlar (strategos'lar, gymnasiarkhos'lar, astynomos'lar vb.), görevliler ve vatandaşlık hakkı gibi konular da ele alınmaktadır.

Basileia: Pergamon Sarayları'nın Bulunduğu Alan (276-285) başlığında Torsten Zimmer, Pergamon Akropolis'inde yapılan kazılarda arkeologlarca farklı kullanım amaçları olmasına rağmen Attalos Sarayları olarak adlandırılan yapılardan ve kazı tarihçelerinden bahseder. Yazar basileia (kraliyet yapıları) adlı bu mahallenin kentin diğer kısımlarından bir sur duvarıyla ayrıldığını ve "saraylar" adlandırmasının değiştirilmesi gerektiğini nedenleriyle açıklamaktadır. Akropolis'te bulunan yapı gruplarının işlevlerini ve evrelerini yorumladıktan sonra buranın basileia olarak bir bütün halinde düşünülmesi gerektiğini belirtir.

Martin Maischberger'in Tiyatro Kompleksi ve Dionysos Tapınağı (288-299) bildirisinin konusu kral II. Eumenes Dönemi'nde (MÖ 197-159) Pergamon Akropolis'inin batı yamacına tek bir yapı kompleksi olarak planlanan tiyatro ve tapınak yapısıdır. Yazar bildiride tiyatro elemanlarının, tapınağın ve terasta yer alan Nişli Yapı'nın tarihlendirilmesine yer vermektedir.

Mimarisi, Iş̧levi ve Heykelleriyle Gymansion (302-317) adlı bildiri Marianne Mathys, Verena Stappmanns ve Ralf von den Hoff' tarafından hazırlanmıştır. Giriş bölümünde gymnasion kısımlarının tanımı, tarihsel ve mimari açıdan gelişimi ve işlevleri hakkında genel bir bilgi sunulmaktadır. Pergamon Gymanasion'unun Mimarisi ve Kullanım Tarihçesi ile Gymnasion'da Gençlerin Örnek Alması Gereken Şahsiyetler başıkları altında iki farklı bölüm ile devam etmektedir. Gymnasion içerisinde bulunan tanrı heykelleri ve onların temsil ettikleri değerler üzerinde durulmaktadır. Örnek alınması istenen krallar ve kahramanlara ait olanların yanında hayırsever 
zenginlere ait çok sayıda onurlandırma heykellerinin de MÖ II. yüzyılın sonundan itibaren gymnasion içerisinde yer bulduğundan bahsetmektedir.

Pergamon Agoraları (320-333) başlığında Marianne Mathys daha önce yayınladığı bir makalesinin yeniden gözden geçirilip kısaltılmış versiyonu olan ve Giriş, Aşağı Agora, Yukarı Agora, Sivil Bir Temsil Olarak Pergamon Agoraları ve Sonuç başlıkları altında ele aldığı bildirisinin ilk bölümünde Pergamon'un sivil kurumları ile Hellenistik bir krallığın yan yana, hatta iç içe neredeyse tek örnek olduğunu belirtip ardından bu iç içe geçişin emarelerinin kendini kent mekânında ne şekillerde belli ettiği sorusuna odaklanmaktadır. Agora'ları sivil yaşamın bir göstergesi olarak ele almadan önce kent mekanları bağlamında değerlendirmeye gidip kent bağlamı, yapıların mimari tasarımı ile kullanım türü ve kullanııılar açısından kıyaslama yaparak aralarındaki farklılık ve benzerlikleri ortaya koymaktadır. Sonuç bölümünde ise gözlemlerini değerlendirmekte, her iki agora'daki arkeolojik bulgular ve epigrafik kalıntıların birbirlerinden çok farklı olması nedeniyle sivil yaşamdaki değişiklikleri tam anlamıyla tespit etmenin mümkün olmadığını ifade etmektedir.

Antik Pergamon Evlerinde Yaşam (336-351) isimli bildiride Ulrike Wulf-Rheidt, kent alanının dik yamaçlarda yer alması nedeniyle Pergamon evlerinin kendine özgü bir plan içerisinde düzenlendiğinden bahseder. Burada yazar, Avlulu Evlerden Peristilli Geniş Evlere - Pergamon Konut Mimarisinin Gelişimi, Çok Odaya Sahip Olma Lüksü ve de Zengin Fakir Yan Yana - Philetairos Kenti Sınırları Iç̧inde Tipik Bir Mahalle başıkları altındaki çalışmalarını okuyucuyla buluşturmaktadır. Yazara göre 1878 yılından beri süre gelen kazılar sonucunda MÖ III. yüzyıl ile MS III. yüzyıl arasına tarihlenen çok sayıda ev kalıntıının ortaya çıkarılması Pergamon evlerinin mimari gelişiminin izlenebilmesine imkân sağlamaktadır. Ancak kent için refah dolu bir dönem olan MS II. ve III. yüzyılda aşağı kentte inşa edilen konutların Bergama'nın altında kalması nedeniyle nasıl göründüğü bilinmemektedir.

Pergamon Nekropolleri (354-375) bildirisinde Ute Kelp, mezarların donanımının, farklı mezar tiplerinin, süslemelerinin ve ölüler için bırakılan hediyelerin antikçağın öteki dünya anlayışına doğrudan bakmamızı sağladığı görüşünü Giriş bölümünde belirtilmektedir. Devamında ise Pergamon Nekropollerini Hellenistik Dönem Nekropolleri, Mezar Anıtları ve Roma ve Bizans Dönemi Nekropolleri başlıkları altında ele alıp değerlendirmektedir. Bildirinin son kısmında tüm çağlar boyunca yörede yaşayan insanların mezarlarına yaşamlarını yansıttığı, özellikle Hellenistik ve Roma İmparatorluk dönemlerinde aileye bağlılıklarından ve memleket için her türlü fedakârlık gibi erdemlerin kahramanlaştırılarak yüceltilmesinden bahsetmektedir.

Eserin içerisinde çokça yer tutan Tanrıların Mekânları isimli bölümde on adet bildiri yer almaktadır: Pergamon'da Tanrılar ve Kutsal Alanlar adlı (380-401) bildiride Soi Agelidis, çok sayıda kutsal alanla donatılan Pergamon'da bu alanların insanlar için gerçekte neler ifade ettiğini ve ne tür ritüellerin gerçekleştirildiğini ele almaktadır. Pergamon'da dini yaşamın sadece bir kısmını kapsayan ve tapınım gören tanrı ve tanrıçalardan bazıları olan Apollon, Zeus, Kentin Tanrıçası: Athena, Asklepios, Kybele/Meter - Ana Tanrıça, Demeter ve Kore, Hera, Dionysos ve Mısır Tanrıları başlıkları altında incelenip genel hatlarıyla okuyucunun bilgisine sunulmaktadır.

Holger Schwarzer'in Attaloslar ve Hükümdar Kültü (404-419) bildirisinin giriş kısmında Büyük Iskender'in kurduğu imparatorluğun dağılması sonrası Antigonos'lar, Seleukos'lar ve Ptolemaios'lar hanedanlıkları tarafından kurulan yeni monarşilerin siyasi alanda duydukları meşru zeminin oluşması için hükümdar kültünden yararlandıklarından bahsetmektedir. O güne değin bilinen 
tek hükümdar kültü tanrılaştırılmış Büyük İskender kültüdür. Attalos'ların hanedanlık kültünü Hellenistik Dönem'deki diğer monarşilerde görülen kültlerden ayıran özellikleri sıralar, Hellenizm'den Roma İmparatorluk Dönemi'ne geçişte Pergamon metropolis'indeki dini yaşamda değişiklikler olduğunu, bununla birlikte hükümdar kültünün hiçbir zaman Roma imparatorluk kültüne rakip görülmediğini vurgular.

Güler Ateş'in Pergamon'da Doğa ve Kült: Ana Tanrıça Inancı ve Doğal Kutsal Alanlar (422435) başıkı makalesi Pergamon'da tapınım gören tanrılardan Ana Tanrıça Kybele inancını konu edinmektedir. Tanrıçanın kutsal alanının mimari yapılara dönüştürülmeden önce bulunduğu doğal ortamların tanımını verdikten sonra Pergamon ve çevresindeki çok sayıda doğal-mimari kutsal alan bulunduğunu belirtir. Buna ek olarak konuyu Kentin Yakın Çevresindeki Coğrafyanın Meter Kutsal Alanları ile İşaretlenmesi ve de Tanrısal Doğa Kent Sınırları İçinde: Pergamon'un Doğu Yamacındaki Doğal Kutsal Alanlar başlıkları olarak iki farklı başlık altında ele almaktadır. Bildirinin sonuç bölümünde kutsal alanların birbirleriyle görsel ilişki içerisinde bulundukları ve bunun ana tanrıça kutsal alanlarının başlıca kriterlerinden biri olup bağımsız birer alan olmalarından ziyade bir bütünün, dini bir coğrafyanın parçaları olduğu belirtilmektedir.

Athena Kutsal Alanı (438-453) başlığı altında Volker Kästner günümüzde Athena Kutsal Alanına ait kalıntıların azlığı nedeniyle buranın ziyaretçilerin algılarında şekillenmesinin neredeyse imkânsız olduğunu vurgular. Roma Imparatorluk Dönemi'ne kadar kentin en saygın kült yeri olarak kalan Athena Kutsal Alanı'na ait mimari blokları ve yazıtları sonradan devşirme malzeme olarak kullanıldıkları yerlerle birlikte değerlendirip kutsal alanın arkeolojik açıdan saptanabilen farklı evrelerini rekonstrüksiyon çizimlerle okuyucuya sunmaktadır.

Sunak Terası (456-477) başlığında Pergamon'un Hellenistik bir krallık başkentine yaraşır intişamına ulaştığı zamanın Kral II. Eumenes dönemi olduğu belirtilerek giriş yapılır. Çalışmasında Volker Kästner sunak terasını ele almakta ve Sunağın Yapılış Tarihi, Sunak Terasının Oluşturulması ve ayrıca da Pergamon Sunağı'nın Mimarisi ve Gigantomakhia Sahneli Büyük Friz gibi başlıklar altında sunak hakkında farkı konulardaki verileri okuyucuyla buluşturmaktadır.

Pergamon Sunağı - Homeros'tan Ilham Alan Bir Zeus Sarayı mı? (480-489) başlıkı incelemeyi Andreas Scholl 2009 yılında yayınladığı bir makaleyi yeniden kaleme alarak oluşturmuştur. Giriş bölümünde yazar, 1906 yılında anıtın mimarisi konusunda yayımlanan çalışma dışında bugüne kadar yapılan tüm bilimsel araştırmaların, anıt kabartmalarının yorumlanmasına yönelik olduğunu belirttiği yazısında anıtın etkileyici görselliğini sağlayan mimari tasarımı ile kabartmalar ve heykeller arasındaki uyumlu ilişki üzerine yoğunlaşmıştır. Scholl sunağı, İon Sunak Geleneği ve Pergamon Sunağı: Ortak Yönler ve Farklar, Sunağın İki Kanadı ve Yunan Stoa Mimarisi, Pergamon Sunağı ve Homeros ve Büyük Friz'in Merdiven Kenarlarındaki İki Köşesi: Dramatik Anlatımın Zirvesi başlıkları altında değerlendirmektedir. Ayrıca Pergamon Sunağı'nın kendi türünde tek ve benzersiz bir anıt olduğunu belirterek bilimsel çalışmalarda bu sunağın bilinen diğer sunaklarla karşılaştııımasının daha uygun olacağını ifade etmektedir.

Jürgen W. Riethmüller'un kaleme aldığı Pergamon Asklepieionu (492-505) yazısında Erken Hellenistik Dönem'de, kent dışında ve bol su kaynaklarının bulunduğu bir vadide kurulan Pergamon Asklepieion'u içerisinde bulunan Asklepios Soter'in (Kurtarıcı Asklepios) sağlık kültünü ele almaktadır. Bu bağlamda; Erken Hellenistik Dönem'de Asklepieion, Kaya Üzerindeki Tapınak ve de Kutsal Alan'ın Yapımının Tamamlandığı Olgun ve Geç Hellenistik Dönem'deki En Görkemli Evresi ve Roma Imparatorluk Dönemi'nde Asklepieion başlıkları altında söz konusu kült mercek 
altına alınmaktadır.

Klaus Nohlen'in Imparatorluk Kültüne Adanmış Bir Tapınak: Pergamon Traianeumu (508521) başlıklı bildirisi, çalışmaların ikinci yılı olan 1879'un Ekim ayında kazılarına başlanan Pergamon Traianeum'unun 20. yüzyılın son çeyreğinde, yapının ayağa kaldırılması kapsamında gerçekleştirilen incelemelerinin sonuçlarına odaklanmaktadır. Bildiri kapsamında Araştırmanın Tarihçesi, Tapınağın Konumu ve Mimarisi, Gelenekçilik ve "Modern" Anlayışı Bağdaştıran Övgüye Değer Bir Yapı ve Anastilosis - Traianeum'un Yeniden Ayağa Kaldırılması başlıkları altında yapılan tüm çalışmaların sonuçları sunulmaktadır.

Ulriche Mania'nın Kızıl Avlu - Pergamon Pantheonu mu? (524-541) başlığılla sunduğu bildiri "Pergamenische Forschungen" serisinde 2011 yılında yayımlanan "Die Rote Halle in Pergamon. Ausstattung und Funktion" kitabından alıntı olup bazı eklemeler yapılarak yeniden düzenlenmiştir.

Pergamon kent tepesinin aşağısında, Hellenistik ve Roma İmparatorluk Dönemi kentlerinin kesiştiği yerde bulunan 270 m uzunluğundaki yapı kompleksini konu almaktadır. Giriş bölümünde burayla ilgili detaylı incelemelerin yapının Bergama'ya gelen ilk araştırmacı gezginlerin ilgisini çekmesine rağmen 1906-1909 yıllarında başladığı belirtilmektedir. Mania, Hadrianus Dönemi sonlarında tamamlandığını düşündüğü yapının tarihlendirilmesinde kullanılan en önemli verilerin mimari süslemeler olduğunu, yapının inşa tarihinin saptanmasının ise tesisin yapılış amacının anlaşılması ve doğru yorumlanmasında bir yol gösterici olduğunu dile getirmektedir. Ayrıca bildiri içerisinde avlunun kenarında bulunan Mııır kökenli destek figürleri konusuna da açıklık getirilmektedir. Bildirinin sonuç bölümünde Hadrianus'un Atina'yı Panhellenion'un merkezi olarak tanıdığı, buradaki birliğe Küçük Asya kentlerinden Smyrna, Ephesos ve Pergamon'un dâhil olmadıkları ve bu nedenle de İmparator'un bir Ionia Birliği'nin oluşması için çaba sarfettiğinin tahmin edildiği ifade edilmektedir. Böylelikle Kızıl Avlu yapı kompleksi farklı kültürlerin ve tanrıların bir araya getirildiği bir oluşumun merkezi olarak düşünülmekte, en azından böyle bir çabanın ürünü olduğu belirtilmektedir.

"Şeytanın Tahtının Bulunduğu Yer" - Pergamon'da ilk Hıristiyanlar (544-551) isimli son derleme Ralf Grüssinger tarafından hazırlanmıştır. Bu bölüm içerisindeki bir pasajda, kendisini "Yuhanna'nın Hizmetkârı" olarak tanıtan ve ismi bilinmeyen bir yazar, kitabında Asya Eyaleti'ndeki yedi Hıristiyan cemaatine hitaben verilen yedi kutsal mesajı aktarmaktadır. Bu cemaatlerden biri de Pergamon'da yaşamaktadır. Kitapta Aziz Yuhanna Pergamon'daki Hıristiyanlara aktarmak üzere İsa'nın kendisine Patmos Adası'nda verdiği mesajı yine İsa'nın emriyle ilettiğini belirtmektedir. Grüssinger, Pergamon'daki ilk Hıristiyanları incelerken Asklepios Soter (Kurtarıcı) kültüne de değinmektedir. Mitolojiye göre tanrı Apollon'un oğlu olan Asklepios ölümlüdür ve öldükten sonra tekrar dirilecektir. Bu özelliğinden dolayı Hıristiyan cemaatin Pergamon'da yayılmaya başladığı dönemde Asklepios kendisine inananların gözünde insanlığın kurtarıcısı bir mesihtir ve Hellen-Roma dini inancına beklenmedik bir canlılık yaşatmıştır.

Ayrıca R. Grüssinger bildirisinde Pergamon'da hâlihazırda bulunan Musevi cemaatinin Hıristiyanlığın kentte yayılmasını kolaylaştırdığını bahsetmektedir. Kentteki ilk Hıristiyanlar hakkında bilgi sağlanabilecek kalıntıların azlı̆ının yer aldığına da değinerek Geç Antik/Erken Doğu Roma dönemlerinden sadece üç kilise yapısı bilindiğini belirtmektedir.

Sonuç olarak bu eseri, W. Radt tarafından hazırlanan ve Anadolu'da kazısı yapılan kentler hakkında yayınlanan kitaplar arasında en iyisi olarak kabul edilen "Pergamon, Antik Bir Kentin Tarihi ve Yapıları" adlı eserin içerik ve kalite olarak devamı şeklinde nitelendirmek abartılı bir 
tanımlama olmasa gerektir. Anadolu Uygarlık Tarihi'nin önemli basamaklarından birisi olup Antikçağın başlıca kentleri içerisinde yer alan Pergamon, arkeoloji dünyası için çok büyük bir değere sahiptir. Anadolu'nun en önemli Hellenistik başkentlerinden biri hakkında yazılan bu eser, içerisinde bulunan bildirilerin yayınsal değeri ve kazı araştırmalarının irdelenip sonuçlandırılarak arşivlenmesi bakımından ele alındığında, Pergamon'un araştırma birikimine önemli bir katkı sunmaktadır. 